\title{
INTELIGÊNCIA, CORPO E EDUCAÇÃO FÍSICA NO PENSAMENTO EDUCACIONAL DE JOHN DEWEY.
}

\author{
Mariclaudia Aparecida Abreu ${ }^{1}$ \\ Carlos Herold Junior ${ }^{2}$
}

\section{RESUMO:}

O objetivo deste trabalho é analisar o pensamento educacional de John Dewey, verificando nele a importância do corpo e da educação física. Para isso, dividimos o texto em três momentos: no primeiro, apresentamos algumas características filosóficas do pragmatismo e levantamos posicionamentos que avaliam a herança de Dewey. No segundo, ocupamonos com a categoria de experiência em Dewey. Por fim, verificamos de que forma as considerações pedagógicas do filósofo americano abordam o corpo e sua educação. Como conclusão, observamos que o pensamento deweyano problematiza dicotomias sobre as relações entre mente e corpo levantadas na modernidade. Com isso, defendemos a importância de uma maior atenção a esse pensamento para se considerar os dilemas que ocupam educadores em geral e professores de educação física, particularmente.

Palavras-chave: Educação Física; John Dewey; Pensamento Pedagógico; Dualismo corpo-mente.

\section{INTELLIGENCE, BODY AND PHYSICAL EDUCATION IN THE EDUCATIONAL THOUGHT OF JOHN DEWEY}

\section{ABSTRACT}

The aim of this article is to analyze the educational thought of John Dewey, verifying the role played on it by body and physical education. For that we divided the text in three different moments: first, we present some philosophical features which can be seen in pragmatism, assessing some ideas on Dewey's heritage. In the second part, the category of experience is studied. Finally, we go through approaches developed by Dewey when they come to body and its education. As conclusion, we support that Dewey's thinking on physical education must be more thoroughly studied. The reason for that is the way Dewey can help teachers in general and physical education teachers particularly, while dealing with some dilemmas regarding intelligence, body and their relationship, which have place since the dawn of modernity.

Key-words: Physical education; John Dewey; Educational thought; body-mind dualism.

\section{INTRODUÇÃO}

O pensamento educacional moderno no esteio das transformações históricas e sociais que levaram ao capitalismo industrial analisou de diferentes maneiras a constituição humana e as formas de se educá-la. Esse pensamento, resguardadas as inúmeras diferenças que o compõem, consagrou uma grande importância à educação do corpo. (HEROLD JR 2004)

A modernidade é reconhecida por vários autores como o momento em que o corpo humano é alvo de um grande conjunto de análises. A filosofia e a ciência modernas, neste ínterim, desenvolveram-se refletindo questões pertinentes à corporeidade e o seu papel na construção de um novo conhecimento e de uma nova sociedade. Entretanto, como já demonstrado em outros trabalhos (HEROLD JR, 2004) a modernidade também abriu 
espaço para análises que secundarizavam agudamente o corpo. Ao ser esse segundo posicionamento considerado, normalmente é aceita a relevância das reflexões entabuladas por Descartes. Se nos atuais meios educacionais, de forma geral, e nos da educação física, especificamente, Descartes é assumido como o responsável pela desconsideração do corpo e dos sentidos na racionalidade e conhecimentos humanos, por outro lado, podemos observar que esses posicionamentos podem ser problematizados.

$\mathrm{Na}$ quarta de suas meditações, afirma Descartes:

[...]agora não apenas sei que existo na medida em que sou alguma coisa que pensa, mas apresenta-se também ao meu espírito uma certa idéia da natureza corpórea; o que faz com que eu duvide se esta natureza pensante que existe em mim, ou antes, pelo qual eu sou o que sou, é diferente dessa natureza corpórea, ou mais, se ambas não são uma mesma coisa. E presumo, aqui, que ainda não tenho conhecimento de nenhuma razão que me convença de uma coisa mais do que outra[...](DESCARTES, 1999, p, 297)

Baker e Morris (2002) analisam a relação entre a forma como Descartes construiu sua visão dualista e a maneira como o dualismo cartesiano foi entendido e debatido, posteriormente. $\mathrm{O}$ que os autores tentam mostrar é que Descartes assumiu a existência da união entre pensamento, corpo e suas mútuas relações, afirmando, porém, a impossibilidade de explicá-las. Explicações contundentes poderiam ser dadas apenas quando corpo e mente eram considerados separadamente. Nesse sentido, dizem os autores: "Não pode haver alguma coisa tal como uma afirmação ou uma teoria que faça a relação entre corpo e alma inteligível" (BAKER e MORRIS, 2002, p.147).

Desde que a filosofia cartesiana lançou as bases para a discussão filosófica e científica moderna, a questão dos contatos e distanciamentos entre corpo e mente ocupou uma grande quantidade de filósofos e educadores. No caso desses últimos, o "problema" cartesiano, existindo e, preferencialmente, sendo resolvido, colocaria condições privilegiadas para se pensar e executar de forma mais refletida as práticas educacionais. Com o início do processo de construção da modernidade o pensamento, as práticas e as instituições educacionais atinadas com o "espírito" da nova sociedade, consideraram de forma relevante a importância do corpo no processo educacional. A justificativa para tanto, sempre girou em torno das consequiências que as atividades corporais teriam para a construção de indivíduos moral e intelectualmente formados nos variados perfis educacionais almejados, que variavam do homem capaz de grandes feitos de Rabelais, do homem feliz de Montaigne, do homem de negócios de Locke, do cidadão virtuoso de Rousseau, do trabalhador produtivo e também do trabalhador revolucionário dos séculos XIX e XX. Essa relevância culminou na criação das bases da disciplina escolar de educação física, no interior dos sistemas nacionais de ensino, no século XIX (HEROLD JR, 2004; LEONEL, 1994).

Com o processo de racionalização da pedagogia que assistimos a partir do século XVI (CAMBI, 1999) e que culminou com a escolarização de toda a sociedade no século XIX (CAMBI, 1999) notamos um esforço de se utilizar educacionalmente a indivisibilidade humana, não negligenciada por Descartes $(1999,2002)$, para se elaborar um conhecimento pedagógico "claro" (DESCARTES, 2002) sobre essa indivisibilidade, o quê Descartes havia afirmado como impossível, gerando, então, o tão debatido problema da união entre corpo e mente. Para Descartes, ou se conhece a mente, a razão, de um lado; ou o corpo, visto como máquina, de outro. A pedagogia do corpo construída na modernidade, assim, oscila entre considerar o corpo como máquina, como suporte da 
intelectualidade e do mundo das idéias, ao mesmo tempo em que tenta teorizar sobre a substancial unidade entre corpo e mente (DESCARTES, 1999, 2002)

Neste artigo, tendo por base esse desenvolvimento do pensamento educacional sobre a educação do corpo, pretendemos desenvolver essa tese, observando-a no pensamento de John Dewey. Justificamos essa opção mostrando no decorrer texto o envolvimento da educação proposta por Dewey no debate filosófico mais amplo, envolvendo a construção do pragmatismo norte-americano, sobretudo, no embate que essa orientação deu aos dualismos erigidos pela filosofia ocidental desde seu surgimento.

Dewey, que viveu no século XX, criticou a educação existente, denominada por ele de tradicional, por se basear em métodos que se utilizavam fartamente da memorização e da "transmissão de conhecimentos", em que o professor era o ponto central de todo o processo educativo. Para abordar esse pensamento focando a questão da educação do corpo, iniciamos o trabalho analisando as bases da filosofia pragmatista. Na segunda parte do texto nos debruçamos sobre um dos principais pontos de sua filosofia: a questão da experiência. Tentamos verificar alguns conceitos e as mudanças de conceitos na compreenssão da experiência e como tal fato influenciou o modo de se pensar a dicotomia entre a teoria e a prática. No terceiro momento apresentararemos as idéias de Dewey que tocam de forma mais direta a relação entre corpo e inteligência, notando o impacto dessa relação nos momentos em que o autor tematiza de forma mais direta a educação física. Mostraremos que essa questão aparece integrada à problemática da relação teoria e prática e a nova concepção de experiência proposta por ele, abordando, mais precisamente, como essa nova forma de pensar contribuiu para a nova prática educativa, de forma geral.

Para alcançarmos esses objetivos e seguindo caminho proposto acima, as obras de Dewey utilizadas como fontes primárias foram: Democracia e educação; Experiência e educação; Vida e educação; Reconstrução em Filosofia; A escola e a sociedade e a criança e o currículo. Além delas, apoiamo-nos em contemporâneos do filósofo e comentadores hodiernos da obra deweiana, tais como James (1979), Teixeira (apud DEWEY 1954), Rorty (1982), Ghiraldelli (2006) Ozmon e Samuel (2004), Schmitz (1980), Cunha e Sacramento (2007).

Justificamos a importância deste trabalho no fato de a questão concernente à educação física no pensamento de Dewey ser pouco analisada. Além disso, nos estudos existentes sobre a temática o foco é diferenciado ao proposto para a condução de nossas reflexões. Dantas Junior (2005) utiliza-se da obra de Dewey para investigar as relações entre Educação Física e a Pedagogia Experimental. Bermond e Ferreira Neto (s.d) mostram que as idéias de Dewey estavam fortemente presentes nas análises sobre a Educação Física, feitas pelos militares entre 1932 e 1957. Souza (2007) menciona o pensamento de Dewey ao analisar a presença do ideário pós-modernista na educação física brasileira. Essa amostra define alguns caminhos já percorridos por estudiosos que investigam a educação corporal e, de alguma maneira, utilizam-se de Dewey para as suas reflexões. Reconhecendo a importância desses trabalhos, temos como proposta evidenciar a relevância do pensamento educacional de Dewey para a problematização de questões concernentes à educação física e que tocam os debates erigidos desde o nascimento da modernidade sobre a separação entre corpo e mente, suas relações e as possibilidades de praticar e teorizar a educação considerando a integralidade humana.

\section{1- O PRAGMATISMO DE DEWEY E ALGUMAS AVALIAÇÕES DOS NEOPRAGMATISTAS.}

$\mathrm{Na}$ Segunda Conferência realizada por Willian James na obra intitulada $O$ que 
significa pragmatismo, ele apresenta o pragmatismo como um método e uma teoria genética sobre o significado da "verdade". E o que ele entende por verdade é o seguinte: "As idéias verdadeiras são aquelas que podemos assimilar, validar, corroborar e verificar. As idéias falsas são aquelas com as quais não podemos agir assim". (JAMES, 1979, p.72). Tal idéia caminha pari passu com a visão de ciência que surgiu no século $\mathrm{XX}$ e que colocou em suspenso muitas das filosofias tradicionais que embasaram suas teorias e métodos em concepções metafísicas "fundacionistas".

O pragmatismo é considerado como "um método de assentar disputas metafísicas[...]" (JAMES, 1979, p.18) O pragmatismo como explica James (1979) está estreitamente ligado à prática. Ele afirma que as nossas crenças têm como intenção realizar regras de ação. Damos significados ao pensamento de acordo com a conduta que este está apto a produzir. Toda idéia se pauta na possibilidade de prática. Dessa maneira, as filosofias metafísicas deveriam ser testadas levando em consideração as conseqüências práticas que causam, pois muitas delas, ao serem submetidas a tal teste, não apresentariam consequiências práticas invalidando-as por fazerem nenhuma diferença tanto do ponto de vista individual quanto do ponto vista social.

Vale observar que o pragmatismo tem como base a atitude empírica, abandonando a razão a priori e as pretensões ao absoluto que buscam essências e origens. Seus proponentes o vêem como um sistema um método em movimento, no qual as teorias são instrumentos para novos caminhos e não respostas de caráter imutável. De acordo com os pragmatistas, sua filosofia está muito mais preocupada em orientar o caminho para uma verdade possível a produzir verdades.

Schmitz (1980) diz que o pragmatismo não é uma filosofia no sentido estrito da palavra, pois busca fundamentar-se em princípios materiais da experiência humana. Filosofia deveria procurar através da razão as causas ou essências das coisas. Porém, seguindo as reflexões de James (1979), o pragmatismo vem romper justamente com essa idéia sobre o que venha a ser a filosofia. A idéia é justamente mexer com os sistemas filosóficos, dar novos ares à filosofia. Desejava-se criar um novo critério para a "verdade".

O pragmatismo representa uma posição contrária às filosofias "essencialistas" em especial a hegeliana, que, apesar disso, é reconhecida como um dos pontos de partida de Dewey. Para fazer essa contraposição os pragmatistas em geral, e Dewey em particular, retomam discussões filosóficas tradicionais, como a questão do racionalismo e do empirismo. Colocam-se contrariamente à primeira, e têm suas bases filosóficas alicerçadas na segunda corrente filosófica. No entanto, é preciso deixar claro que o pragmatismo se propõe apenas absorver dessas correntes as idéias que eles acreditam poderem contribuir para o seu sistema filosófico. Concorda em partes com várias teorias na medida de sua "utilidade".

Haja a vista o fato de que a própria ciência adapta o método indutivo, compreende que as teorias não são uma transição da realidade. Elas têm suas aplicações na medida de sua utilidade, não devendo ser defendidas pelo seu caráter de verdade, mas na medida em que "funcionam". Dewey e os demais pragmatistas, dizem que a verdade em nossas idéias e crenças significa a mesma coisa que significam na ciência. As idéias (elas próprias, não são senão partes de nossa experiência) tornam-se verdadeiras na medida em que nos ajudam a manter relações satisfatórias com outras partes de nossas experiências, para sumariá-las e destacá-las por meio de instantâneos conceptuais, ao invés de seguir a sucessão interminável de um fenômeno particular (JAMES, 1979, p.22). E James (1979) segue explicando que as opiniões e crenças vão se transformando e se alterando na medida em que vão surgindo novas verdades. Uma teoria vai superando a outra por fornecimento de soluções. 
De forma geral essa é a base filosófica do pensamento de Dewey, no desenvolvimento do qual ele pretendeu colaborar. A importância dessa colaboração é avaliada tanto positivamente, quanto negativamente. Rorty (1982), como um dos analistas e continuadores de Dewey, faz uma avaliação da herança filosófica de deweyana, apontando, também, os avanços conseguidos e limites não superados pelo filósofo escolanovista.

Inicialmente, Rorty (1982) tenta definir precisamente as intenções de Dewey afirmando que ele objetivou elaborar "[...]descrições da gênese histórica e cultural dos problemas usualmente apelidados de 'metafísicos', interpoladas com recomendações de várias peças de jargão que, pensa Dewey, nos ajudam a ver a irrealidade (ou, pelo menos, a evitabilidade) desses problemas."(1982, p.131) A superação desses "falsos" problemas se daria à medida que a postura de "expectador de todos os tempos e eternidade"(Rorty, 1982, p.133) fosse deixada para trás.

Nesse sentido, Dewey se colocaria com intenções semelhantes a alguns desdobramentos filosóficos do século $\mathrm{XX}$, tais quais os de Habermas e de Foucault (RORTY, 1982, p.135). Além disso, complementa Rorty: “[...]o seu principal inimigo era a noção de Verdade como adequação da representação, noção que viria a ser atacada mais tarde por Heidegger, Sartre e Foucault.”(1982, p.147)

Rorty (1982) atribui à questão da experiência em Dewey um dos pontos fulcrais de sua obra. A obra filosófica de Dewey, diz Rorty (1982), é uma grande tentativa de definir e descrever a experiência humana sem cair nos tradicionais dualismos elaborados nos dois mil anos de filosofia ocidental: "[...]ele é um dos poucos filósofos do nosso século cuja imaginação foi suficientemente expansiva para imaginar uma cultura modelada segundo linhas diferentes das que desenvolvemos no Ocidente durante os últimos anos." (Rorty, 1982, p. 145) Definindo de forma mais específica o valor das reflexões de Dewey, diz Rorty, (1982) que ele nos mostrou que era possível:

[...]eliminar problemas epistemológicos eliminando a premissa que a justificação tem de repousar em qualquer coisa diferente das práticas sociais e das necessidades humanas. Para dizer, como Dewey quer fazer, que ganhar conhecimento é resolver problemas, não precisamos de encontrar 'continuidades' entre sistemas nervosos e pessoas, ou entre 'experiência' e 'natureza'. (RORTY, 1982, p.142)

Um dos limites que Rorty aponta na obra deweyana é o "o seu hábito de anunciar um arrojado novo programa positivo quando tudo o que oferece, e tudo o que precisa de oferecer, é o criticismo da tradição.”(1982, p.138) Ghiraldelli Jr. (2006) observa que os críticos do pragmatismo associam-no a uma espécie de oportunismo que advogaria que somente a utilidade caracterizaria a verdade ou que a verdade nada mais seria que conveniências particulares e momentâneas. O problema do pragmatismo de Dewey, diz Ghiraldelli Jr. (2006) é que essas críticas foram argumentadas por Dewey evocando a "noção de representação"(p.166), o que significou que Dewey não teria conseguido superar os problemas por ele mesmo tinha levantado. Entre outros, afirma Ghiraldelli Jr (2006), fora Rorty (1982) que começou a tematizar as críticas feitas ao pragmatismo, colocando-o em condições de proporcionar novas formas de problematizar velhos dilemas. Para Ghiraldelli (2006), o que os atuais desdobramentos do pragmatismo ofereceram foi a possibilidade de escapar tanto da idéia de "verdade como representação" quanto do ceticismo e relativismo, limites presentes em outras tentativas de questionamento da herança moderna. No meio dessa trajetória, diz o autor, Dewey ofereceu bases importantes mesmo sem ter desenvolvimento radicalmente suas idéias. 


\section{2- A EXPERIÊNCIA E A IMPOSSIBILIDADE DOS DUALISMOS EM DEWEY.}

Para se estudar a filosofia deweyana no que tange à educação do corpo é necessário investigar a categoria "experiência". Pois uma das características mais interessantes da sua teoria educacional é justamente o novo olhar e significação sobre a importância da experiência para aquisição do conhecimento. O que é experiência? E como ela está relacionada com a verdade ou o conhecimento?

Dewey afirma que as concepções sobre o termo experiência vão se modificando ao longo da história social e explica o porquê do antagonismo entre experiência e o "verdadeiro" conhecimento. Nas obras Democracia e Educação(1959) e Reconstrução em Filosofia(1959), Dewey analisa a questão da teoria e da prática na educação através de investigação das modificações pela qual passou a concepção de experiência.

Ele realiza essa tarefa retomando os gregos para explicar a separação entre a teoria e a prática. Cunha e Sacramento (2007) ao analisarem o pensamento de Dewey, mostram que, várias vezes, ele fez um paralelo entre o pensamento dos modernos e dos gregos com a intenção de comparar as duas sociedades e mostrar como o conhecimento foi produzido e aceito. E uma das questões levantadas por eles com relação à educação é a constatação de que "[...]antagonismo entre duas formas de educar, uma voltada para o trabalho útil, e outra para uma vida de lazeres".(CUNHA e SACRAMENTO, 2007, p. 280). Na realidade é uma educação para a classe superior e outra forma de educação para a classe inferior, o que denota uma profunda ligação entre conhecimento, sua transmissão e a organização da sociedade. Dewey tem clareza que as transformações que são exigidas nas estruturas educacionais apresentam um íntimo relacionamento com as transformações sociais e econômicas (2002, p.18). Isso, no entender de Dewey, explica o fato de a educação, ao longo de sua trajetória histórica, ter sido refém de um modo de pensar e agir cotidianos que opõe o saber ao fazer, justificada pela separação da sociedade em classes antagônicas:

Assim como se contrapõem o trabalho para ganhar a vida e o gôzo dos
lazeres, também se faz o mesmo com a teoria e a prática, a inteligência e
a ação. Estes últimos antagonismos proclamam, indubitàvelmente, as
mesmas condições sociais que geram a primeira oposição; mas
determinados problemas de educação relacionados com êles tornam
desejável examinar claramente as conexões e a pretensa separação entre o
saber e o fazer. (DEWEY, 1959, p. 288)

A separação entre o saber e o fazer, como afirma Dewey, se vê apoiada na idéia de que o conhecimento resulta de algo mais elevado que a atividade prática e cotidiana. A filosofia tradicional acredita que "[...] a experiência nunca se ergue acima do nível do particular do contingente e do provável”. (DEWEY, 1959, p.98). Ela identificava a experiência com interesses puramente práticos, ligados aos interesses materiais e aos sentidos. Quanto ao conhecimento, este existia independente da prática e provinha de algo imaterial. Todavia, segundo Dewey, essa maneira de proceder e analisar o conhecimento, estava ancorada na crítica aos costumes e à tradição como padrão para o conhecimento e à conduta.

Como afirmam Cunha e Sacramento (2007), tanto Platão como Aristóteles consideravam a experiência como sinônimo de interesses, "meramente", práticos; por isso é compreensível que para Dewey os gregos tenham estabelecido a dicotomia entre a razão e as paixões e entre o ócio e o trabalho. E para derrubar tão forte oponente, a experiência deveria parecer algo imperfeito e falho, e a "razão" a única digna de crédito. Para subordinar a experiência à tutela da razão, Platão e Aristóteles teriam mostrado a natureza instável e insuficiente da experiência. Para Cunha e Sacramento (2007) essa análise 
paralela das sociedades serve para que Dewey defenda sua tese de que o pensamento antigo precisa ser superado:

O Estagirita tinha razão, afirma Dewey ao 'admitir a inferioridade e a subordinação da simples habilidade de execução e da simples acumulação de produtos exteriores' perante o 'entendimento', mas cometeu um 'equívoco teórico' ao presumir a 'separação necessária dessas duas coisas'. Ocorre que tal equívoco ainda persiste na contemporaneidade, devendo, agora, ser corrigido. (CUNHA e SACRAMENTO, 2007, p. 281).

Continuando a acompanhar a análise de Cunha e Sacramento (2007), notamos que eles afirmam que para Dewey o problema está em continuarmos a aceitar uma forma de pensar que se originou na base de uma sociedade que não existia mais. $O$ filósofo reconhece que diferenças sociais entre o seu tempo e o tempo antigo poderiam explicar alguns dos posicionamentos por ele criticados nos gregos. Entretanto, a produção escravista não é tomada como importante nesse debate. Tanto na análise que Cunha e Sacramento (2007) fazem de Dewey, como nas análises do próprio Dewey, trata-se de uma ultrapassagem conceitual, de idéias limitadas e limitantes. E a superação desse quadro pintado sobre a Grécia não aconteceria nem mesmo quando a inteligência fosse vista como um meio de dominar a natureza, afinal, nesse pensamento persistia a postura que imputava a não utilização da inteligência por aqueles que extraiam as "utilidades" da natureza. A separação entre razão e experiência na Grécia nega a necessidade que uma teria da outra, como se fossem duas coisas totalmente distintas. Este modo de pensar deu origem ao debate entre o racionalismo e o empirismo. Foi esse debate, entre outras coisas, que justificou a separação entre o corpo e a mente:

O conhecimento, a apreensão intelectual ou teórica de uma coisa acha-se, portanto, fora dos domínios da vicissitude, do acaso e da diversidade. Nada falta a verdade; ela é inacessível às perturbações do mundo dos sentidos. Ela trata do eterno e do universal. E o mundo da experiência pode ser regulado por ela, pode ser consolidado e ordenado somente pela sujeição à sua lei racional. (DEWEY, 1959, p. 292).

Tal pensamento influenciou profundamente a educação, como Dewey afirma e a história da educação demonstra. Ocorreu um desprezo pelas ciências físicas e pelos sentidos, como também pelas coisas concretas, particulares e pelo corpo. O que valia era um conhecimento universal ideal.

Nas sociedades medievais essas considerações continuam vigentes, mesmo que tenham sido submetidas a revisões e mudanças. A experiência era de pouca importância frente ao conhecimento das coisas sobrenaturais. Aqui a dicotomia entre teoria e prática também se relaciona com a distinção de classes:

Quando acrescentarmos a êste motivo a força adveniente da natureza literária da educação romana e da tradição filosófica grega, e a isso juntarmos a preferência pelos estudos que claramente extremavam a classe aristocrática das classes inferiores, poderemos facilmente compreender o formidável influxo da preferência pelas coisas 'intelectuais', em detrimento das 'práticas', não só nas filosofias educacionais, como também nas escolas superiores. (DEWEY, 1959, p. 292). 
Se na Grécia antiga, para quebrar a força da experiência que estava arraigada aos costumes usou-se a razão, Dewey reconhece que os modernos fizeram o procedimento ao contrário: para derrubar o valor da razão inculcada nos costumes e no valor da autoridade, apelou-se para a experiência "[...] como prova final e critério último". (DEWEY, 1959, p.101) Na era moderna, a experiência adquiriu um novo status, isso devido ao novo método científico, que não via mais a razão como única forma válida de adquirir conhecimentos, aliás, a razão e as noções a priori, para alguns, passaram a significar formas vazias e sem significação, apoiada em "autoridades". A experiência deveria preencher e dar significação e valor às teorias:

A experiência perdeu a significação prática que tivera desde Platão. Ela cessava de significar meios de fazer e realizar e tornou-se o nome de qualquer coisa intelectual e cognitiva. Passou a designar a aquisição de material que servisse de lastro e limite para o exercício do raciocínio. (DEWEY, 1959, p. 293).

O grande influenciador dessa nova concepção de experiência foi, no entender de Dewey, John Locke. Porém, argumenta o educador americano que o empirismo inglês ocasionou um intelectualismo ainda maior. Suas idéias se encaixavam perfeitamente com o dualismo de seu tempo. Também acreditava que o objetivo da educação não era só o de absorver e armazenar conhecimentos, mas também formar as faculdades pessoais, como a atenção e a memória, observação, abstração e generalização.

Ele via o individuo como uma tabula rasa, que deveria ser preenchida. "Era realista em sua asserção categórica de que qualquer que fosse o material, provinha este do exterior - é idealista, por ter como meta educativa a formação das faculdades intelectuais". (DEWEY, 1959, p. 66). Nega, portanto as faculdades inatas. No entanto, a teoria de Locke é rebatida por Hume, diz Dewey: "Mas após Hume ter pôsto em relevo, com meridiana clareza, que a análise de crenças em sensações e associações deixava as idéias e instituições 'naturais' na mesma posição em que os reformadores haviam colocado as idéias e instituições 'artificiais', então a situação mudou." (DEWEY, 1959, p.102).

Cunha e Sacramento (2007) assinalam que o discurso de Dewey, que volta às origens do problema que opõe razão e experiência, tem como intenção mostrar que a sociedade do início do século XX ainda persistia na dicotomia entre razão e conhecimento, de um lado, e necessidades materiais de outro, o que teve por consequiência uma educação mecânica, física e outra intelectual. Isso levou Dewey a afirmar que as filosofias são produtos sociais, elaboradas a partir das necessidades e limites daquelas sociedades, mas que, nem por isso, são fatos inalteráveis ou questionáveis.

Com isso em mente, ele observava uma nova concepção que começava a surgir com relação à experiência e à razão, ou como Dewey afirma "[...] o lugar da razão na experiência". (Dewey, 1959, p. 102). Foi uma mudança de método e de conteúdo, que se consolidou com o desenvolvimento da biologia. É, então, percebido que toda vida implica atividade continuada e adaptada ao meio ambiente. A experiência ganha, portanto, uma nova condição: o de atividade, com intenção e reflexão. O novo conceito de experiência superaria a contradição entre racionalismo e empirismo: "O conhecimento não é algo de separado, e auto-suficiente, mas está implicado no processo pelo qual a vida se sustenta e envolve. Os sentidos perdem seu lugar de portões do conhecimento, para ocupar o posto, que de direito lhes compete, de estímulos à ação." (DEWEY, 1959, p.105). A razão é segundo Dewey "inteligência experimental” (DEWEY, 1959, p. 111).

A razão começa a ser vista, então, como um processo contínuo. E mais que isso, que todo conhecimento resulta da união entre teoria e prática: "[...] a ciência é formada por meios e fins, um componente estritamente material ou instrumental e um componente 
intelectual, sendo que ambos, quando devidamente integrados, contribuem para obtenção de conhecimentos certos e provados". (CUNHA e SACRAMENTO, 2007, p. 281). Os autores falam em conjugação "intelectual-material" e em conjugação "teoria- prática".

Obviamente, essa nova concepção de razão, experiência e instrumentalização do pensamento forma-se junto com o desenvolvimento do pragmatismo. Dewey traz esse modo de pensar para a pedagogia e fala de uma experiência consciente, inteligente, sendo esta a responsável por acabar com a dicotomia entre a teoria e a prática e, consequentemente, entre a inteligência e o corpo.

\section{3 - EXPERIÊNCIA E EDUCAÇÃO DO CORPO: PROBLEMATIZANDO O DUALISMO CORPO E MENTE.}

Dewey (s.d.) consagra um conjunto importante de reflexões sobre a questão referente ao dualismo corpo e mente. Seu objetivo é mostrar a falsidade do problema explicitando como ele, historicamente, colocou-se. Para isso, também, ele dirige sua atenção para a antiguidade clássica, passando pelo mundo medieval, chegando à definição moderna do "problema", bem como as diferentes "soluções" que até então tinham sido propostas.

Sem reconhecer diferenças importantes e tomando a tradição idealista de Platão na hora de fazer sua análise histórica do pensamento antigo, o filósofo americano começa observando que na sociedade grega a alma era o elemento que caracterizava a vida, pelo fato de a alma possuir automovimento, movendo-se por si mesma. Entretanto, adverte Dewey (s.d.), os gregos prestavam grande atenção ao corpo humano por considerá-lo uma espécie de "atualidade" das potencialidades oferecidas pela natureza física (p.249).

Seguindo a argumentação de Dewey (s.d.), vemos que ele constata que essas considerações sofrem alterações com as mudanças que levaram à idade média. Nesse momento, diz o filósofo americano, o corpo passa a ser considerado como "terreno, carnoso, luxurioso e cheio de paixões; o espírito é próximo a Deus, perene; a carne é corruptível; o espírito incorruptível.” (p. 249)

Interessantemente, nem na antiguidade nem no mundo medieval a questão da relação entre corpo e mente não se colocava, diz Dewey (s.d.). Esse "problema" é posto com toda intensidade no nascimento da modernidade, quando a natureza deixa de ser explicada em termos de potencialidade e atualidade. É aqui, diz Dewey (s.d.), que "mente e matéria se colocaram uma em oposição a outra[...]" (p.251) É para esse momento, também, que Dewey (s.d.) direciona suas críticas aos dualismos tradicionais da filosofia, demonstrando os limites não somente desses dualismos, mas das "soluções" engendradas para contorná-los:

O formalismo e irrealidade do problema permanece, porém, nas teorias que foram oferecidas como soluções. Elas variam do materialismo de Hobbes, o aparato de almas, glândulas pineais, espíritos animais de Descartes, ao interacionismo, harmonia pré-estabelecida, ocasionalismo, paralelismo, idealismo pan-psiquico, epifenomenalismo e élan $\operatorname{vital}[\ldots](\mathrm{p} .252)$

Ciente, então, de todas as possibilidades de solução para o problema relativo ao relacionamento entre mente e corpo, Dewey (s.d.), como pragmatista, defende a idéia de que esse dualismo foi construído pela incapacidade de reconhecer distinções de "níveis de complexidade crescente e intimidade de interações entre eventos naturais. A idéia de matéria, vida e mente representarem tipos separados de seres é uma limitação que surge, assim como muitos erros filosóficos surgiram, de uma substanciação de funções 
eventuais." (p.261) Com isso, Dewey (s.d.) defende a inexistência do problema, invalidando, assim todas as pretensas soluções até então elaboradas. É isso que ele afirma:

Quando a vida e a mente são reconhecidos como características da altamente complexa e extensiva interação de eventos, é possível dar um status de existência natural a qualidades, sem cair nos erros da ciência grega. Fenômenos psico-físicos e fenômenos mentais superiores podem ser admitidos em sua realidade empírica, sem recurso a quebras dualistas na continuidade histórica e existencial.265-6

Para definir de forma mais precisa a superação do "problema" do dualismo entre mente e corpo, Dewey (s.d.) fala de um processo de crescimento de complexidade entre os diferenciados processos de manutenção da vida. Para exemplificar essa afirmação Dewey (s.d.) explica que o dualismo corpo e mente é o mesmo que problematizar a relação entre uma planta que cresce e a terra na qual ela é cultivada (p.275), ou o mesmo que afirmar que um urso hibernando sobreviveria sem obter na natureza as substâncias que ele precisa para o seu longo período de "independência". (p.279)

\section{1- O DUALISMO CORPO E MENTE E SEU IMPACTO NAS ESTRUTURAS E PRÁTICAS EDUCACIONAIS.}

Considerando o predomínio de esquemas dualistas nas análises filosóficas, Dewey (1979) tece duras críticas às estruturas escolares então vigentes. Para ele, o principal problema é a distância que se construiu entre a vida cotidiana dos alunos e a rotina escolar. Ele diz que "[...]a escola fez-se uma espécie de instituição radicalmente diferente de qualquer outra forma de organização social." (p. 4)

Ele se ocupa, então, em diagnosticar como essa distância se manifesta para tentar fazer com que a escola não se movimente como um mundo separado. Essa tensão entre separação e indivisibilidade entre a organização escolar e a organização cotidiana da vida, polariza o debate que Dewey (1979) institui entre "educação tradicional" e "educação progressiva"(p.4)

Nessa tensão, várias constatações servem para explicitar a forma como a escola desconsiderava a vida cotidiana da criança. A primeira é a distância que se coloca entre o "saber amadurecido e acabado do adulto" e a "experiência e capacidade do jovem" (p.6). Argumenta Dewey (1979) que enquanto esse distanciamento continuasse a ocorrer, não haveria qualquer forma de "participação mais ativa" do aluno naquilo que era ensinado. Como corolário dessa situação, vemos que o pensador norte-americano diagnostica a não existência de respeito às individualidades na estrutura escolar, o autoritarismo reinante nas escolas e a escalada dos problemas relativos à indisciplina dos alunos.

É no interior dessas observações críticas que Dewey (1979) retoma o conceito de experiência. A base da educação tradicional é justificar suas atitudes, seus trabalhos, seus esforços e autoridade para construção ou transmissão daquilo que a criança vai precisar no seu futuro e que não é visto por ela importante no seu presente. Ou seja, para Dewey (1979), sacrifica-se a experiência cotidiana infantil em nome de um futuro inexistente e totalmente mediado por expectativas sociais que não dizem respeito ao mundo infantil. Por isso, a educação "tradicional" recorria às punições, às reprovações para "estimular" o bom cumprimento das regras escolares. Por conta dessa limitação facilmente perceptível no mundo escolar, Dewey (1979) afirma que "Considero que a idéia fundamental da filosofia de educação mais nova e que lhe dá unidade é a de haver relação íntima e necessária entre os processos de nossa experiência real e a educação". (p.8) O interessante é observarmos 
que esse apego ao "futuro" e a desconsideração do presente experiencial da criança e jovem coloca em questão, dessa maneira, a busca de justificativas para a transmissão de todo o conjunto de saberes acumulados historicamente e construídos em diferentes temporalidades. Se formar para o futuro deve tornar-se relevante para os desafios presentes de quem aprende, o mesmo se dá, por exemplo, com os conhecimentos transmitidos pela história, pensa Dewey: "Como poderá o jovem conhecer e familiarizar-se com o passado de modo tal que este conhecimento se constitua poderoso fator de sua apreciação e sentimento do presente vivo e palpipante?" $(1979$, p.11)

Nesse conjunto de questionamentos ao mundo escolar "tradicional", vemos que Dewey, em seu esforço por considerar o "presente vivo e palpitante", olha com grande simpatia os jogos, esporte e demais práticas recreativas. Para ele, essas atividades conseguem fazer o que horas de imposição, castigos e transmissões de conhecimentos desvinculados da experiência infantil, não conseguem fazer sem grandes prejuízos: o aprendizado da necessidade e do valor das regras sociais (p.47). O que os jogos e atividades recreativas contemplam é a necessidade de movimento por parte da criança, analisada por ele como um traço componente de sua "real natureza" (p.60) Dewey (1979) não desconsidera que a reflexão e o pensamento, para acontecerem, sobretudo, com níveis cada vez maiores de complexidade, necessitam do silêncio ou de uma determinada "ausência" de movimento: "A velha frase 'pare e pense' está certa psicologicamente". (p.63) Entretanto, até essa "verdade", diz Dewey, para ser aprendida, deve passar pela consideração concreta da criança e não ser mais um ponto de apoio para um dos componentes mais presentes da escola, que ele define da seguinte forma:

A limitação posta à atividade de movimento pelos arranjos rígidos da típica sala de aula tradicional, com as suas fileiras de carteiras e a arregimentação militar dos alunos, que só podiam se mover por certos sinais estabelecidos, representava uma grande restrição à liberdade intelectual e moral. (1979, p.59) 


\section{2- A VIDA, A EDUCAÇÃO, A INTELIGÊNCIA E O CORPO.}

Dewey analisava que a escola não tinha uma ligação intrínseca com a vida. Ele pretendia uma teoria educacional que estivesse vinculada à prática social, uma educação que não negasse a criança enquanto corpo e vontade, que não desprezasse as atividades práticas:

A história de teoria de educação está marcada pela oposição entre a idéia
de que educação é desenvolvimento de dentro para fora e a de que é
formação de fora para dentro; a de que se baseia nos dotes naturais e a de
que é um processo de vencer as inclinações naturais e substituí-las por
hábitos adquiridos sob pressão externa. (DEWEY, 1979, p.3).

Na citação acima Dewey está falando do empirismo e do racionalismo. Na escola tradicional, adepta do método racionalista o aluno é um receptor, que apreende por meio dos livros e do conhecimento dos mais velhos. Trata-se de um saber estático, que não colocava desafios. É como se aluno fosse um corpo isolado para o qual seria transferido um saber já elaborado, sem participar do processo.

A educação nova, como afirma Dewey, relaciona os processos de experiência real do aluno e a educação. Valoriza-se o individual e interesse pessoal do aluno e faz disso instrumento para aquisição do conhecimento. Portanto, para Dewey, a educação não se separa da vida. Ora, se a vida não é mais que um tecido de experiências de toda sorte, se não podemos viver sem estar constantemente "experimentando", é que a vida é toda ela uma longa aprendizagem. Vida, experiência, aprendizagem - não se podem separar. Simultaneamente, vivemos, experimentamos e aprendemos. (Dewey, 1980, p. 115).

Seria essa, em especial, a nova característica que a educação institucionalizada deveria reconhecer. Educação que considera os processos vitais e a vida do aluno, assim como afirma que esta se desenvolve continuamente, assim como na vida. Enquanto ser vivo está "condenado" a aprender, pois toda experiência conduz a um novo aprendizado. É o que afirma Anisio Teixeira, ao prefaciar uma das obras de Dewey:

Um dos grandes méritos da teoria de educação de Dewey foi o de restaurar o equilíbrio entre a educação tática e não formal recebida diretamente da vida, e a educação direta e expressa das escolas, integrando a aprendizagem obtida através de um exercício específico a isto destinado (escola), com a aprendizagem diretamente absorvida nas experiências sociais (vida). (apud DEWEY, 1954, p.13).

A educação tradicional se preocupava com a teoria; a nova educação se preocupa mais com a prática, na medida em que considerava a experiência como fonte de conhecimento. A educação é entendida por Dewey como reconstrução da experiência cotidiana. Dewey diz: "É feliz aquêle que não teve para progredir profissional e intelectualmente, de desaprender o que veio aprender na escola". (DEWEY, 1979, p. 41). Critica a separação entre vida e educação, o fato da escola ser uma instituição isolada, uma organização sem vínculo com o social. Sobre isso, Anísio Teixeira, comenta: "As escolas passam a constituir um mundo dentro do mundo, uma sociedade dentro da sociedade. Isto, no melhor dos casos, que, no pior, de coisas inúteis e estúpidas, não relacionadas com a vida nem com a própria realidade". (apud DEWEY 1954, p.13).

Ou seja, Dewey restaurou um princípio que não era considerado: o de que a educação só tem sentido se ela não perde seu componente básico de relação com os processos de produção e manutenção da vida. E a vida humana é, necessariamente, um processo de educação, de formação e aquisição de experiências em que a corporalidade 
possui um valor central. Muitas coisas ocorrem porque o ser vivo é um corpo que lhe permite contatos com o meio e com outros corpos. Isso, por sua vez, possibilita adquirir experiências, ir se adaptando a elas e as modificando por meio da inteligência: "Com o renovar da existência física, também se renovam, no caso de seres humanos, as crenças idéias, esperanças, venturas, sofrimentos e hábitos". (DEWEY, 1959, p. 2).

O corpo, enquanto vida e individualidade, dependerá do grupo social inserido as experiências posteriores. O nascimento e a morte dos indivíduos implicam a necessidade da educação. $\mathrm{O}$ fato de os seres humanos não serem eternos os levam a educar as gerações futuras. É necessário entender o homem enquanto um corpo temporal e uma inteligência que se constrói e reconstrói através da educação:

Por um lado, existe o contraste entre a imaturidade dos recém-nascidos membros do grupo - seus únicos futuros representantes - e a maturidade dos membros adultos, que possuem os conhecimentos e seguem os costumes do referido grupo. Existe, por outro lado, a necessidade de que não sòmente sejam fìsicamente conservados em número conveniente êsses membros imaturos, como também que se iniciem nos interêsses, intuitos, conhecimentos, habilidades e costumes dos componentes adultos; e se assim não fôsse, findaria a vida característica da comunidade. (DEWEY, 1959, p. 2 e 3).

A educação é garantia da comunidade, e é por meio dela que é superada a diferença entre adultos e crianças:

Com o progresso da civilização aumenta a distância entre a capacidade originária do imaturo e os ideais e costume dos mais velhos. Para reproduzir-se a vida do grupo já não bastam o simples crescimento físico e a consecução dos meios de subsistência. Requer-se esforço deliberado e árdua reflexão. Os sêres que nasceram não só inscientes dos objetivos do grupo, como também completamente indiferentes a êsse respeito, precisam conhecê-los e interessar-se ativamente pelos mesmos. A educação e só a educação suprime essa distância. ([...]) A sociedade subsiste, tanto quanto a vida biológica, por um processo de transmissão. (DEWEY, 1959, p. 3).

O desenvolvimento humano é complexo e atrelado ao meio social: aprende-se com os outros e por meio de outros, e o que possibilita essa dinâmica existencial é a constituição humana física e intelectual. Como é possível perceber nas palavras de Dewey:

De fato, os sêres humanos novos são tão incapazes que abandonados a si mesmos, sem a direção e o amparo dos mais velhos, nem mesmo adquiririam as habilidades rudimentares necessárias à existência material. Comparado com os filhos de muitos animais inferiores, os seres humanos têm tão minguadas aptidões, que a própria habilidade requerida para alimentação física precisa ser adquirida por meio do ensino. Quanto mais no que diz respeito à aquisição das capacidades técnica, artística, científica e moral da humanidade. (DEWEY, 1959, p. 4).

A educação formal na concepção de Dewey não consegue perceber que mente e corpo trabalham indissociavelmente. $\mathrm{E}$ que se valorizando os aspectos coletivos $\mathrm{e}$ individuais as matérias de estudo serão mais significativas para os alunos justamente por contemplarem essa indissociabilidade, cotidianamente vivenciada. A atividade física, segundo Dewey, também é intelectual, na medida em que envolve aprendizado. $\mathrm{E}$ 


\section{ainda mais, ele vê os órgãos do corpo, em especial as mãos como instrumentos, como condições para o ato de conhecer.}

Além de considerar a atividade física como educativa, também demonstra a importância de partir da realidade, para que o aprendizado não se torne mero simbolismo. Cabe então, ao educador, fornecer materiais que despertem o desejo pelo conhecimento, através de jogos e brincadeiras, ou do interesse prático.

\section{3- ESCOLA E A EDUCAÇÃO FÍSICA: CORPOREIDADE E ORGANISMO.}

Segundo Schmitz (1980), para Dewey não há diferença entre o ser corporal e o espiritual, existindo apenas uma diferença de grau. Ele não concorda com Dewey, pois vê na teoria do educador americano um reducionismo do homem a um ser biológico: "Educar apenas por necessidade, como se o ser humano não valesse por si mesmo, visando garantir a perpetuação da espécie, é muito pouco. Isto parece reduzi-lo a um ser precipuamente biológico". (SCHIMITZ, 1980, p. 49).Para Dewey só existia, de acordo com essa análise, o conhecimento sensível, o que redundaria na enfatizada necessidade da reconstrução da experiência, entendida como mera empiria.

No entanto, acreditamos que a argumentação feita por essa crítica desvia o foco de Dewey, que é a não separação entre conhecimento sensível e inteligível, da mesma forma que para ele não existe a distinção entre a mente e o corpo. Tendo por base a análise acima feita sobre a relação entre vida e educação, poderíamos perguntar, problematizando as afirmações de Schimitz (1980): afinal, será que é pouco ser biológico? Dewey mostra que considerar a manutenção e produção da vida como uma "redução" ao biológico é um dos resultados dos esquemas dualistas da filosofia, construídos desde os gregos. Para Dewey ser biológico e ser humano são práticas complementares. É isso que ele demonstra em suas obras, uma das quais possui o sugestivo título de "Experiência e natureza" (s.d.), publicada em 1958, sinalizando que para o pensador americano a forma como ele considera o "biológico" é radicalmente diferente dos variados dualismos da filosofia que posicionam natureza e cultura, corpo e mente, razão e sentidos de forma dicotômica.

Vemos que em Vida e Educação, Dewey (1954) analisa a importância das atividades corporais fazendo algumas considerações de caráter mais metodológico do trabalho didático. Por exemplo, ao explanar sobre os tipos de interesse educativo fala sobre a atividade física, comenta que "Sempre que a atividade física tiver de ser aprendida, apresenta valor intelectual." (p.73) Além dessa afirmação, podemos encontrar alguns tópicos em sua análise que evidenciam claramente a importância que o filósofo americano creditava às atividades corporais e à educação física: "A importância das ocupações escolares que envolvem o exercício dos sentidos e dos movimentos" (p.74) "Os órgãos dos sentidos são simplesmente os caminhos dos estímulos para as reações motrizes." Conhecimento e seu desenvolvimento ocorrem pela adaptação do estímulo sensorial e da reação motriz”(p.74) “O grande valor de brinquedos, jogos e ocupações.”(p.74)

A ênfase de Dewey na valorização por parte da escola da experiência concreta do aluno não secundariza o reconhecimento de que qualquer tentativa de reconstruir essa experiência na escola, por melhor sucedida que venha a ser, apresentará limites e não conseguirá contemplar plenamente a riqueza ela possui na vida cotidiana de todos nós. (2002, p.21) Entretanto, em alguns momentos essa intensidade está presente na escola, de forma "natural": nos momentos de brincadeira e de prática de esportes, por exemplo (2002, p.24). A arte também é vista como uma possibilidade concreta de contemplar no mundo escolar um envolvimento mais autêntico dos alunos (p.76). O que essas atividades 
apresentam de proximidade com a experiência cotidiana dos alunos, dificilmente conseguiria ser proporcionado pelas atividades da sala de aula, sobretudo, quando a condução educacional se dava em moldes tradicionais.

Dewey (2002) acaba por valorizar imensamente o caráter ativo da aprendizagem, dando grande valor à manipulação, ao envolvimento, à construção, em suma, aos trabalhos manuais. Entretanto, justamente para evitar reducionismos recorrentes quando essa importância é posta em evidência, ele adverte:

[...] na instituição escolar, estas ocupações não devem reduzir-se a meros expedientes práticos ou formas de ocupação rotineira que visem à aquisição duma mestria técnica no campo da culinária, da costura ou da tecelagem, mas deverão ser, isso, sim, centros activos de descobertas científicas sobre os materiais e processos naturais, pontos de partida donde as crianças serão levadas a compreender o desenvolvimento histórico do homem.(DEWEY, 2002, p.28)

Dewey, ao evidenciar a importância dos trabalhos manuais ou das atividades práticas na escola, era alvo de críticas, principalmente, aquelas que o reprovavam por ser materialista ou por priorizar atividades que seriam típicas de classes subalternas (2002, p.31) e que desvalorizariam o aspecto intelectual e de engrandecimento cultural e moral, vistos como atribuições escolares.

Ao criticar a escola tradicional por sua desconsideração da dimensão experiencial dos alunos manifesta na corporeidade e no envolvimento prático como mundo, Dewey afirma que na escola tradicional, o aluno chega com um "corpo saudável" e uma "mente mais ou menos predisposta", tendo apenas o primeiro acesso às estruturas escolares. Ou seja, a escola tradicional, ao valorizar o intelectualismo, a imobilidade, a desconsideração do tempo presente em nome do tempo futuro, acaba por inviabilizar justamente aquilo que era seu objetivo principal: o desenvolvimento intelectual. Com isso, Dewey defende que "O que pretendemos é que a criança venha para a escola com todo o seu corpo e toda a sua mente e que deixe a escola com um corpo ainda mais saudável e uma mente ainda mais completa." (2002, p.72)

A luta de Dewey contra os dualismos filosóficos, sobretudo, o dualismo entre corpo e mente sistematizado na modernidade, não quer dizer a não adoção de pensamentos e práticas educacionais já recorrentes na história da educação. Retomando a tese exposta no início deste trabalho que tange à educação física na modernidade, se, de um lado, Dewey inova ao defender o fato de a educação como um todo sempre ser corporal, prática e pessoal, de outro, quando fala da educação física dos ginásios, não titubeia em retomar idéias que até mesmo Descartes havia questionado ${ }^{3}$. Ao falar sobre aspectos concernentes à arquitetura escolar, fala dos ginásios, afirmando que "[...] enquanto o ginásio tal como o entendemos se dedicaria trabalhar e corrigir as dificuldades específicas e tentaria mais conscientemente edificar de forma completa um corpo perfeito, como residência de uma mente perfeita. (2002, p.72) (sem grifos no original)

\section{CONCLUSÕES}

Rugiu (1998) vê uma "nostalgia do mestre artesão" quando analisa o fato de a educação moderna ter se formado com um pensamento que valorizava a integralidade em um momento em que a indústria parcializava, cada vez mais, as capacidades humanas. Nesse raciocínio, Dewey possui um lugar especial. Diz Rugiu (1998) 
A nostalgia da qual falamos é ainda mais evidente em Dewey, também ele na condição de sonhar uma "humanização" da sociedade industrial, recuperando, através da educação "progressiva", um desalienante espírito artesanal, exatamente enquanto o taylorismo e as primeiras linhas de produção faziam picadinho dos restos da tradição dos mestres de arte. (RUGIU, 1998, p.12)

A constatação do estudioso italiano é interessante, mesmo que ele não ofereça maiores subsídios para entendê-la. Poderíamos complementar a afirmação acima, questionando o fato de o corpo e sua educação, no pensamento de Dewey, receberem grande atenção. Por que considerar o corpo e sua educação em um momento em que a prática social materializava as habilidades e sutilezas corporais dos artesãos na potência tecnológica do mundo industrial? Saviani (apud RUGIU, 1998), também considera esse "descompasso", problematizando-o no prefácio do trabalho de Rugiu (1998), mas respondendo a questão que o autor italiano bem elaborou no decorrer de toda obra:

A educação, portanto, segundo a hipótese que estamos formulando, contém em sua própria essência (pela própria natureza da coisa) características que a aproximam da forma própria do trabalho artesanal, impossibilitando a sua plena objetivação, exigência essa requerida pela forma de produção especificamente capitalista. Talvez esteja ai, ao menos no caso de Marx, a razão da atração exercida pelo artesanato. Nesse caso não se trataria, propriamente, de um saudosismo pelo passado mas do germe da educação do futuro (MARX, 1968, p.554) que, entretanto, não brota do artesanato mas do próprio sistema fabril que, embora se opondo diametralmente a esses fermentos de transformação (IBIDEM, p.559), os desenvolve por contradição. (SAVIANI apud RUGIU, 1998, p.5)

No que tange à educação física, as relações entre as transformações do mundo do trabalho e as transformações da educação não podem ser estabelecidas de forma direta ou mecânica (HEROLD JR, 2008). Dewey elabora seu pensamento educacional em que o capitalismo ampliava de forma acelerada a parcialização do trabalho pelo cronômetro e pela linha de montagem. É nesse contexto que o corpo aparece como um dos elementos centrais da educação "renovada", tanto como base da idiossincrática dimensão experiencial, a ser considerada pela escola, como organismo, como "residência de uma mente perfeita" (DEWEY, 2002, p.72) Ou seja, o pensamento de Dewey sobre a educação física sintetiza as hesitações sobre essa modalidade educacional que foram debatidas desde o início da modernidade e já elaboradas por Descartes no plano estritamente filosófico, sendo radicalizadas justamente no momento em que o domínio do "espírito gerencial" taylorista dominava e esquadrinhava o "corpo mecânico" do trabalhador industrial.

Essas reflexões nos levam a propor como sugestão para futuros estudos, a proximidade e os distanciamentos filosóficos entre a luta de Dewey contra os dualismos e o desenvolvimento do materialismo histórico. Woolfson (1982) ao fazer uma avaliação da idéia de Engels sobre a centralidade do trabalho na formação do homo sapiens, argumenta de uma forma a endossar a nossa suspeita de haver uma grande proximidade entre o valor da categoria experiência em Dewey, e o primado da atividade prática, concreta, em suma, do trabalho, na argumentação de Engels e Marx. Diz Woolfson (1982):

Uma "relação inversa" emerge entre a transformação da forma física da espécie humana e a modificação na forma de trabalho. Nos anteriores hominídios modificações insignificantes na técnica eram acompanhadas por substanciais modificações na morfologia. No Homo Sapiens, maiores 
transformações na técnica e formas de atividade têm pequena importância para sua forma física. Os termos dessa "relação inversa" são estritamente materialistas, mas podem facilmente dar condições para uma visão idealista do cérebro como o fator primário do desenvolvimento, enquanto, como Engels afirma, "as mais modestas produções da mão trabalhadora foram recuadas como fundamento (background)". Foi precisamente nessas bases que Engels originalmente formulou seu ensaio sobre as origens humanas e criticou seus contemporâneos pelo seu idealismo (1982, p.77).

Tanto para Dewey como para Engels a primazia do intelecto, da mente, configurava-se uma limitação perante o envolvimento cotidiano no enfrentamento dos desafios postos para a manutenção da vida. Obviamente, essa semelhança não deve secundarizar diferenças existentes no plano político que impulsionam cada um dos autores. Negar esse debate com o pragmatismo deweyano, entretanto, empobrece a consideração de um pensamento pedagógico marxista, pois não aborda questões presentes em ambas matrizes de pensamento e que tocam questões educacionais relevantes. Elas são concernentes ao caráter ativo do ensino, da relevância do conteúdo que se ensina e do valor da corporalidade para a construção das individualidades e da construção de uma nova sociedade.

Com isso, pretendemos ter mostrado a importância do pensamento educacional de Dewey para as questões debatidas por aqueles que se interessam pela educação física escolar, pelo fato de o pensador americano sistematizar em sua proposta pedagógica dimensões comumente vistas como antípodas por pedagogos e professores. Essas dimensões (a experiencial e a orgânica, ou a da cultura e da natureza) no desenvolvimento do pensamento educacional moderno aparecem conjugadas de forma tensa, mas fornecem os subsídios para as práticas, as teorias e suas relações, conscientes ou não, no cotidiano escolar da educação física. Resultantes de debates intensificados nos albores da modernidade, essas questões ganharam relevo no momento de sua escolarização no final do século XIX e nas primeiras décadas do século XX e, nisso, o pensamento de Dewey possui um valor que deve ser aprofundado em outras análises.

\section{REFERÊNCIAS BIBLIOGRÁFICAS}

BAKER, G.; MORRIS, K. J. Descartes'Dualism. London and New York: Routledge, 2002.

BERMOND, M. T.; FERREIRA NETO, A. Um olhar sobre as propostas dos militares para a educação física escolar na revista de educação física (1932-1957). PROTEORIA, disponível em http://www.proteoria.org/textos/2005_cemef_magda.pdf Acesso em 10/10/2008.

CAMBI, F. História da pedagogia. São Paulo: Editora da Unesp, 1999.

CUNHA, M. V.; SACRAMENTO, L. F. Os gregos nas estratégias argumentativas de Jonh Dewey. Revista Brasileira de Educação.v. 12, n. 35, maio/agosto. 2007. 
DANTAS JUNIOR, H. S. A pedagogia experimental e a educação física: aproximações às formulações de John Dewey. 2005 Disponível em http://hpopnet.sites.uol.com.br/dewey.pdf Acesso em10/10/2008

DESCARTES, R. Discurso do método; Regras para direção do espírito. São Paulo: Editora Martins Claret, 2002.

DESCARTES, R. Descartes.São Paulo: Editora Nova Cultural, 1999.

DEWEY J. A escola e a sociedade e a criança e o currículo. Trad. Paulo Faria, Maria João Alvarez e Isabel Sá. Lisboa: Relógio D’água Editores, 2002.

DEWEY J. Experiência e educação. Trad. Anísio Teixeira. 3 ed. São Paulo: Companhia Editora Nacional, 1979.

DEWEY J. Experiência e natureza, lógica: a teoria da investigação; A arte como experiência; Vida e educação; Teoria da vida moral. trad; Murilo Otávio Rodrigues Paes Leme, Anísio S. Teixeira, Leônidas Gontijo de carvalho. São Paulo: abril Cultural, 1980.

DEWEY J. Vida e Educação. Trad. Anísio S. Teixeira. 6. ed. São Paulo: Melhoramentos, 1954.

DEWEY J. Experience and nature. New York: Dover, s.d.

DEWEY J. Democracia e educação. Trad. Godofredo Rangel e Anísio Teixeira. 3 ed. São Paulo: Companhia Editora Nacional, 1959.

DEWEY, J. Reconstrução em filosofia. 2. ed. Tradução António Pinto de Carvalho. Nacional: São Paulo: 1959b.

GHIRALDELLI JR, P. Filosofia da educação. São Paulo: Editora Ática, 2006.

JAMES, W. Pragmatismo e outros textos. Trad. Jorge C. da Silva; Pablo R. Mariconda. São Paulo: Abril Cultural, 1979.

HEROLD JR, C. A educação física na história do pensamento educacional: apontamentos. Guarapuava/Curitiba: Edunicentro e Fundação Araucácia, 2008.

HEROLD JR, C. Corpo, pensamento educacional e práxis: a "teoria" e a "prática" da educação física nos albores da modernidade. Acta Scientiarum. Human and Social Sciences, Maringá, v. 26, n. 2, p. 221-230, 2004.

LEONEL, Z. Contribuição á história à escola pública: elementos para a crítica da teoria liberal da educação. Campinas, Universidade Estadual de Campinas, 1994. (Tese de Doutorado).

OZMON. H. A.; SAMUEL, C. Fundamentos Filosóficos da educação. $6^{\circ}$ ed. Trad. Ronaldo Cataldo Costa. Porto Alegre: Artemed, 2004. 
RORTY, R. Consequências do pragmatismo. Lisboa: Instituto Piaget, 1982.

RUGIU, A. A nostalgia do mestre artesão. Campinas-SP: Autores Associados, 1998.

SCHIMITZ, E. F. O pragmatismo de Dewey na Educação: esboço de uma filosofia da educação. Rio de Janeiro: Livros Técnicos e Científicos, 1980.

SOUZA, L. C. Ideologia pós-moderna e a produção do conhecimento em educação física. In: XV Congresso Brasileiro de Ciências do Esporte e II Congresso Internacional de Ciências do Esporte, 2007, Recife-Brasil. Congresso Brasileiro de Ciências do Esporte, 2007.Disponível em http://www.cbce.org.br/cd/resumos/126.pdf

Acesso em 10/10/2008

WOOLFSON, C. The labour theory of culture: a re-examination of Engels's theory of human origins. London, Boston and Henley: Routledge and Kegan Paul, 1982.

\footnotetext{
${ }^{1}$ Graduada Filosofia e acadêmica de Pedagogia na Unicentro, Guarapuava. Professora de filosofia no Estado do Paraná.

${ }^{2}$ Professor Adjunto do Departamento de Pedagogia da Unicentro, Guarapuava-PR.

${ }^{3}$ No Discurso do Método (2002), diz Descartes: “[...]eu descrevera a alma racional, mostrando que esta não pode, de modo algum, derivar do poder da matéria, assim como as demais coisas de que falara, mas que deve ter sido expressamente criada. Não basta que esteja alojada no corpo, como um piloto no navio. É preciso, para mover os membros, que esteja estreitamente junta e unida a ele, com sentimentos e apetites semelhantes aos nossos e que lhe permitem compor um verdadeiro homem.” (p.58) (sem grifos no original)
}

Artigo recebido em: 11/11/2008

Aprovado para publicação em: 17/02/2009 